
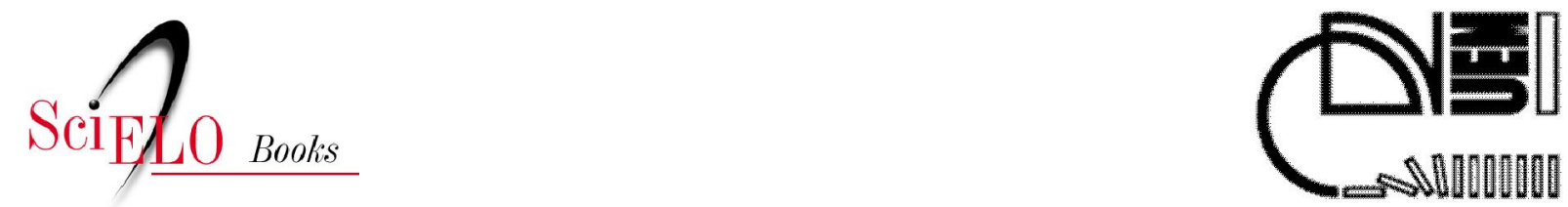

\title{
9 A modernização do campo e o êxodo rural
}

\author{
Angelo Priori \\ Luciana Regina Pomari \\ Silvia Maria Amâncio \\ Veronica Karina Ipólito
}

\section{(1) (1)(1)}

All the contents of this chapter, except where otherwise noted, is licensed under a Creative Commons Attribution-Non Commercial-ShareAlike 3.0 Unported.

Todo o conteúdo deste capítulo, exceto quando houver ressalva, é publicado sob a licença Creative Commons Atribuição Uso Não Comercial - Partilha nos Mesmos Termos 3.0 Não adaptada.

Todo el contenido de este capítulo, excepto donde se indique lo contrario, está bajo licencia de la licencia Creative Commons Reconocimento-NoComercial-CompartirIgual 3.0 Unported. 


\section{9}

\section{A modernização do campo e o êxodo rural}

Em função da transição da economia de base agro-exportadora para uma economia urbano-industrial, a partir da crise do café em 1929 o Estado passou a exercer forte presença no desenvolvimento econômico, por meio de políticas macroeconômicas e desenvolvimentistas que atendiam aos interesses da oligarquia cafeeira. $\mathrm{O}$ interesse pela industrialização e o anseio em aumentar a produção nacional resultaram no processo de modernização da agricultura brasileira nos anos de 1960, culminando na manutenção dos problemas no campo e a existência de conflitos localizados pela posse da terra. A modernização agrícola no Estado do Paraná foi acompanhada de mudanças que historicamente ocorrem na instalação da base técnica ao campo, como problemas sociais, dentre eles, o êxodo rural, a concentração fundiária a partir dos anos de 1970 e o desemprego no campo.

No Brasil, até as primeiras décadas do século $\mathrm{XX}$, as muitas economias regionais estavam mais inseridas na lógica do mercado externo do que articuladas entre si em território nacional. Representavam, dessa forma, o complexo mundo rural brasileiro, baseado em uma economia agro-exportadora e a procura externa por produtos agropecuários, pois até então o território brasileiro apresentava-se desarticulado e o país 
se baseava em uma economia nacional formada por várias economias nacionais (OLIVEIRA, 1990).

A partir de 1850, a implantação da Lei de Terras no Brasil e a proibição do tráfico negreiro (que resultaria na implantação do trabalho livre no país) marcaram transformações profundas na economia agrícola, principalmente com a consolidação do café, como principal produto exportador, e a incorporação, a partir de 1870, de um novo sistema de trabalho: o colonato, com o estabelecimento de unidades familiares, formadas por imigrantes, no Oeste do Estado de São Paulo. A formação do complexo cafeeiro aumentou a divisão social do trabalho e estimulou a divisão entre campo/cidade e agricultura/indústria na economia brasileira.

Em âmbito nacional o período de fins do século XIX até os anos de 1930 destacou-se como momento áureo na economia cafeeira e na ampliação da divisão do trabalho, com aceleração do desenvolvimento de atividades urbanas, além do crescimento de setores vinculados à economia cafeeira.

\section{Participação do Estado, industrialização e centralização política}

A quebra da Bolsa de Valores de Nova York em 1929 afetou diretamente a economia cafeeira no Brasil. Essas transformações incentivaram o redirecionamento da economia brasileira para uma industrialização tardia. No campo, houve uma diversificação da produção agrícola, com destaque para a produção sucroalcooleira e o cultivo de algodão no Estado de São Paulo. Além dessas atividades agrícolas diversificadas que ganharam espaço com a crise cafeeira, também se destacaram o açúcar no Nordeste, a borracha no Norte amazônico, a pecuária no Triângulo Mineiro e o cultivo de alguns cereais, como o trigo e o arroz, no Sul do país. 
Nesse momento o Estado assumia o papel de regulador na economia brasileira, ao mesmo tempo em que a agricultura no país vivenciava um processo de modernização, resultante de mudanças técnicas no campo e o direcionamento da produção agrícola de acordo com a demanda da economia urbano-industrial. As características espaciais, sociais e econômicas sofreram mudanças significativas, principalmente em razão da transição de uma economia agrário-exportadora para uma economia urbana e industrial. A partir dos anos de 1940 é possível notar a estruturação do mercado de trabalho, com o aumento dos empregos formais e o surgimento de novos segmentos na economia.

Nos anos entre 1940 e 1960 a economia brasileira caracterizou-se pela industrialização substitutiva das importações, por uma revalorização do café em âmbito internacional, seguida de uma supervalorização da moeda nacional e da concentração industrial na região Sudeste do país. Principalmente nos Estados de São Paulo e Paraná, desenvolveu-se o cultivo do café, impulsionado pela procura deste produto no mercado mundial daquele momento.

O modelo de substituição das importações fez com que o Brasil alcançasse o capitalismo industrial. Esse processo foi decorrente da diminuição do valor e o volume das exportações desde a crise econômica de 1929, obrigando a se produzir localmente os produtos que antes eram importados. Essas alterações modificaram o contexto político nacional, e os trabalhadores urbanos ganharam maior importância. $\mathrm{O}$ que marcou essa transformação foi a passagem de um sistema de base agro-exportadora para uma sociedade urbana e industrial. O Estado voltou-se para o fortalecimento de uma indústria de base, sendo o agente primordial da modernização econômica. Por um lado, o modelo de substituição das importações propiciou o desenvolvimento de diversos ramos da indústria. Mas, por outro lado, a estrutura industrial (maquinaria) estava ultrapassada. Em síntese, o sistema de industrialização por 'substituição das importações' atendia ao mercado local, no entanto, não tinha forças para se tornar competitivo no exterior (GAGGERO; GARRO; MANTIÑAN, 2001). Além do mais, esse sistema provocou 
mudanças apenas no setor industrial, enquanto que o sistema agrícola brasileiro manteve as mesmas formas de exploração da produção. Não obstante o crescimento e o aumento da variedade da produção agrícola entre as décadas de 1930 e 1960, as tecnologias no campo nesse período caminharam a passos lentos, apenas agregando técnicas modernizantes a partir dos anos de 1950 e de 1960.

\section{O campo e as discussões em torno do desenvolvimento econômico nacional}

Nos anos de 1960 era evidente o desafio da sociedade brasileira diante da urgência em re-estruturar alguns mecanismos administrativos, políticos, fiscais e agrários. A eminente concentração da propriedade fundiária, as condições de trabalho precárias no campo, principalmente em relação ao baixo índice de assalariamento, associadas a uma base técnica que deixava a desejar, renderam muitos debates em relação à necessidade de uma Reforma Agrária no Brasil no início dos anos de 1960.

Embora houvesse divergências, nesse momento era nítida a distinção entre duas linhas de interpretação. Por um lado, apoiado, sobretudo, pelo Partido Comunista Brasileiro (PCB), pela Comissão Econômica para a América Latina (CEPAL) e pela Igreja Católica, havia aqueles que desejavam que os trabalhadores tivessem o acesso a terra, garantido por lei por meio de um programa de reforma agrária e, por outro lado, como Delfim Neto e um grupo de economistas da Universidade de São Paulo (USP), havia os defensores de uma modernização do campo como maneira de se estimular a produção e criar condições de vida melhores aos trabalhadores rurais, não havendo, nesse caso, a necessidade de se organizar a reforma agrária.

Com o golpe militar de 1964, o programa de reforma agrária foi deixado de lado e todo o debate foi vinculado às reformas das funções da agricultura no desenvolvimento econômico brasileiro. Sob as bases 
do regime militar e com a luta dos trabalhadores pela reforma agrária amordaçada, o Estado se responsabilizou na formulação e desempenho de políticas macroeconômicas, voltadas para o aperfeiçoamento das técnicas na agricultura brasileira. Essas transformações possibilitaram o processo de modernização 'conservadora' na produção rural brasileira.

Entre os anos de 1965 e 1980 a agricultura no Brasil, além de estar articulada à economia urbano-industrial e ao setor externo, passou a sofrer intervenções ainda mais frequentes do governo nacional. Uma das alternativas do governo para controlar a produção agrícola nacional foi elaborar programas de financiamento, como a implantação do Sistema Nacional de Crédito Rural, em 1965.

Desde os anos de 1950 era possível notar um processo de modernização da agricultura que estava, no entanto, dependente da importação de produtos, máquinas e insumos agrícolas do exterior. Nesse sentido, o próprio termo modernização pode ser aplicado para se definir um "processo de transformação na base técnica da produção agropecuária no pós-guerra a partir das importações de tratores e fertilizantes num esforço de aumentar a produtividade" (SILVA, 1996, p. 19). Contudo, o processo de modernização apenas se consolidou na década de 1960, momento em que a produção agrícola brasileira se integrou tecnicamente ao setor urbano e industrial, visando a ganhos econômicos em maior quantidade.

À implantação do Sistema Nacional de Crédito Rural em 1965, seguiu-se a estruturação de novas instituições nas décadas de 1960 e 1970, como a Empresa Brasileira de Pesquisa Agropecuária (EMBRAPA) e a Empresa Brasileira de Terras (EMBRATER). Além disso, novas iniciativas aceleraram a modernização no campo brasileiro, como a instalação do Programa de Apoio à Atividade Agropecuária e as Políticas de Garantias de Preços Mínimos. Assim, entre os anos de 1960 e 1980, a agricultura brasileira tornou-se parte fundamental do projeto de urbanização e industrialização do país. 
No entanto, esse projeto de modernização não ocorreu de forma homogênea em todo o Brasil. Houve uma concentração dos investimentos nas regiões Sul, Sudeste e parte do Centro-oeste. Além do mais, a opção pela estruturação de uma economia urbano-industrial pelo governo brasileiro privilegiou a transferência de recursos do campo para o financiamento do desenvolvimento do projeto nacional.

Houve, dessa forma, uma 'modernização desigual e conservadora' da agricultura brasileira, com destaque para a preferência na contemplação dos programas do governo a grandes proprietários de terras, o direcionamento de uma economia agrícola para a exportação e a prioridade de aplicação das políticas governamentais para a agricultura nas regiões mais desenvolvidas do país (GONÇALVES NETO, 1997). O resultado dessas práticas, associado ao consumo de produtos industriais pela economia agrícola e até mesmo à formação de um processo de industrialização da agricultura brasileira, impulsionou nos anos de 1970 a formação dos complexos agroindustriais.

Dessa forma, a agricultura brasileira ficou a reboque da indústria. A produção agrícola não se configurou mais como um setor autônomo a partir desse momento, pois passou a depender da integração entre atividades agrícolas e atividades industriais.

\section{A modernização da agricultura no Paraná e seus impactos no meio rural}

O processo de modernização da agricultura no Paraná ocorreu entre fins da década de 1960 e início dos anos de 1970. Nesse momento, a economia cafeeira estava em crise em função do excesso de oferta desse produto no mercado internacional, além da concorrência sofrida com as produções cafeeiras da África e da Colômbia. Contribuíram ainda para a queda da produção as pragas e alterações climáticas, como a ferrugem e as geadas, que marcaram a crise do café nesse momento. 


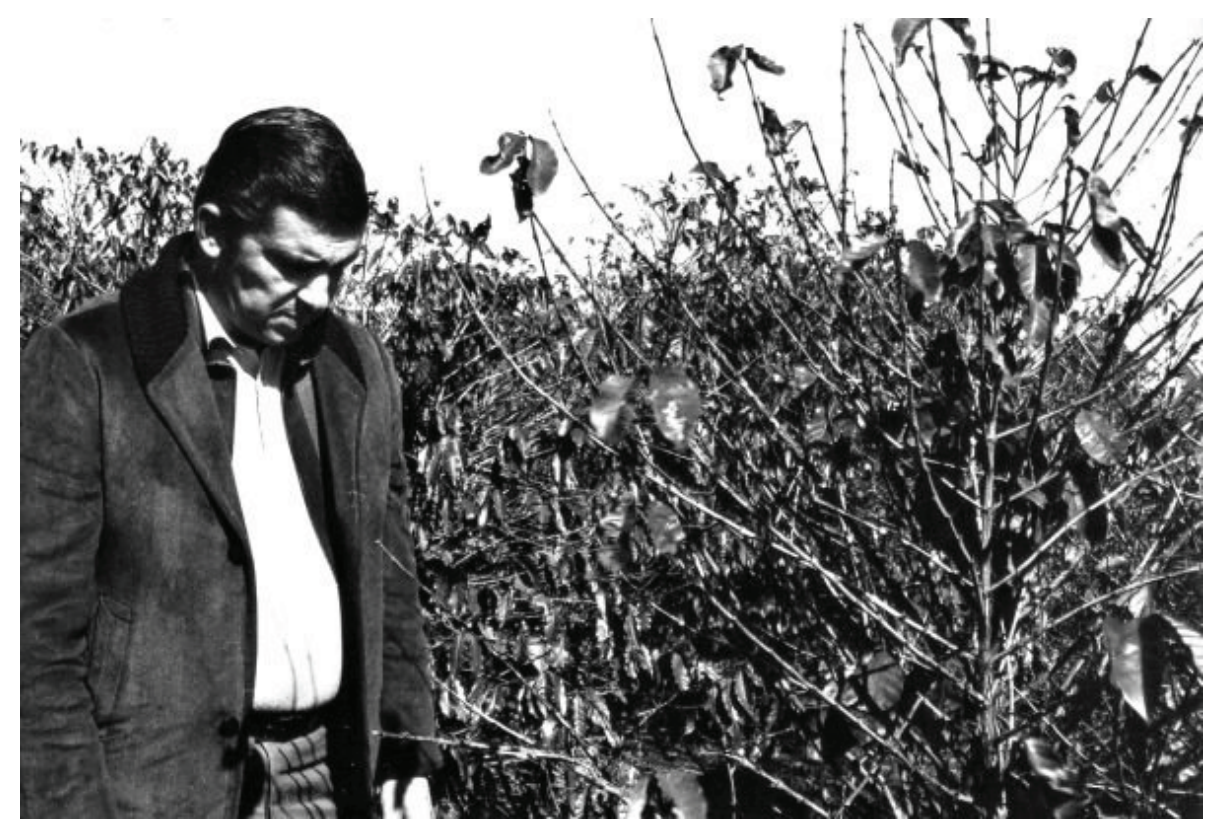

Figura 1: Jaime Canet, governador do Paraná (1975-1979), observa os efeitos da chamada 'geada negra de 1975' que dizimou as plantações de café no Estado e provocou o êxodo de milhares de pessoas

Fonte: Museu da Imagem e do Som do Paraná (Arquivo MIS/PR).

Até meados da década de 1970, o café era o principal produto da economia paranaense. A produção cafeeira no Estado correspondia à metade da produção nacional e à terça parte da produção mundial. Boa parte desses cafeeiros estava localizada nas regiões Norte e Noroeste do Paraná, locais onde o processo de modernização aplicou-se de maneira mais intensa (MORO, 2000).

Já na década de 1960, quando o mercado cafeeiro dava sinais de crise, foi criado, pelo Governo Federal, o Grupo Executivo de Racionalização da Agricultura. Essa iniciativa tinha por objetivos erradicar e renovar as plantações de café a fim de racionalizar e tornar sua produção mais eficiente. Além disso, também propôs a diversificação de produtos agrícolas, estimulando, principalmente, a produção de oleaginosas, bem como a integração dessa produção com o setor agroindustrial. 


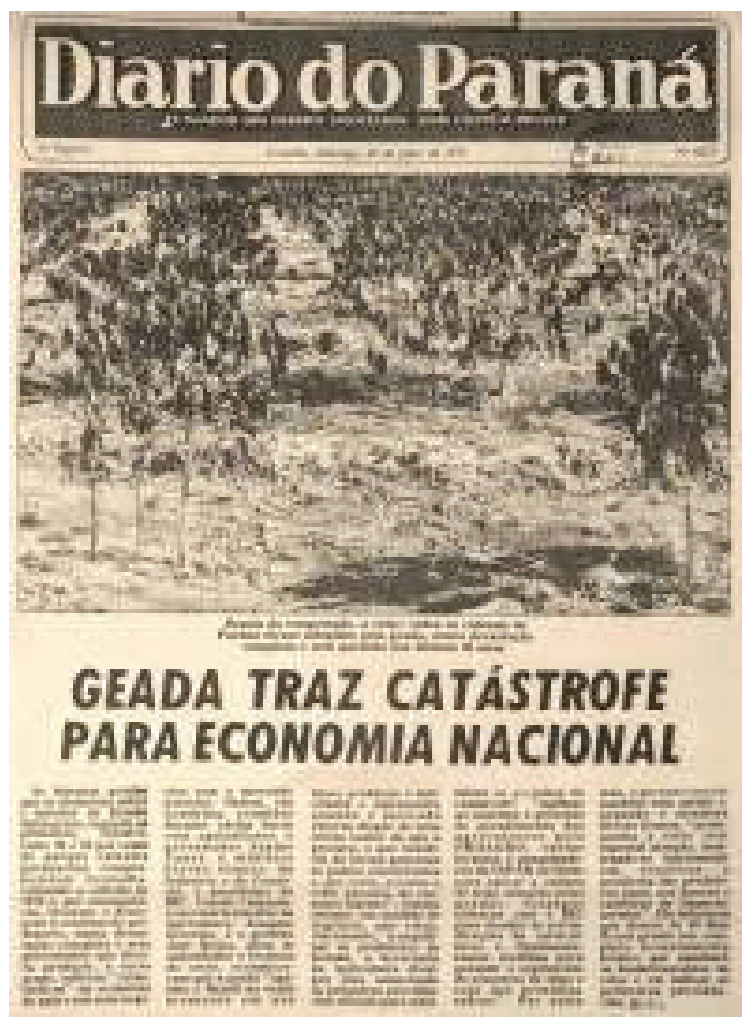

Figura 2: Reportagem do jornal curitibano Diário do Paraná de 20 de julho de 1975, noticiando os prejuízos no campo, com a geada de 1975

Fonte: Arquivo Público do Estado do Paraná

Diante desse cenário de transformações, o processo de modernização agrícola no Estado do Paraná se tornou mais evidente. Houve uma significativa mudança no processo de transformação técnica para a produção agrícola "através dos seguintes aspectos: mecanização, eletrificação, irrigação e conservação do solo, uso de fertilizantes e agrotóxicos, além de outros peculiares a certas culturas" (MORO, 2000, p. 30).

Alguns números que envolvem atividades ligadas à agricultura nos dão uma dimensão da modernização técnica e produtiva que ocorreu no Paraná, sobretudo na década de 1970. O número de tratores, por exemplo, 
sofreu uma alteração de 338,3\% entre os anos de 1970 e 1980. Da mesma forma, houve elevação em outras atividades, como "no número de arados de tração mecânica $(379,4 \%)$, no número de estabelecimentos com uso de força mecânica (1.134,9\%), no consumo de óleo diesel (604,9\%), no consumo de energia elétrica $(47,0 \%$ e $687,6 \%$ no período de 1980 a 1985)" (MELO, 2011, p. 68). Mesmo no próprio Paraná o processo de modernização agrícola não ocorreu de forma homogênea, pois os efeitos desse processo foram sentidos de forma mais intensa no Norte e Oeste do Estado.

Em termos sociais, o aumento do número e utilização de tratores, além de outros implementos e insumos agrícolas, eliminou muitos empregos no campo e engrossou as migrações para as cidades. Houve nesse momento uma intensificação do êxodo rural, com uma população excluída se direcionando para cidades de maior porte na região, para São Paulo, para a região metropolitana de Curitiba, além das regiões de fronteira.

É importante reconhecer que a transferência da população do campo para a cidade não foi um fenômeno provocado apenas pela modernização agrícola. A substituição do café por culturas oleaginosas diminuiu significativamente a utilização de mão de obra no meio rural, já que a soja e o trigo, por exemplo, não eram plantações permanentes, pois estavam inclusas no sistema de rotação de culturas, além de contarem com um elevado nível de mecanização, dispensando a utilização de grande quantidade de mão de obra.

As lavouras de café sofreram uma queda de $59 \%$ entre os anos de 1970 e 1985, dando lugar ao cultivo do trigo e da soja. Além dessas, verificou-se também uma elevação das pastagens, aproximadamente em 32\%, principalmente no Norte e Noroeste do Paraná (MELO, 2011).

A concentração fundiária também marcou o processo de modernização paranaense e em números representou somente nos anos de 1970 a eliminação de 100.385 estabelecimentos agropecuários. Houve também a redução de proprietários e arrendatários, mas com aumento da 
área explorada. As mudanças em relação à modernização agrícola, que ocorreram no Paraná entre os anos de 1970 e 1991, proporcionaram a redução da população rural em 49,7\% no Estado, enquanto que, apenas no Norte do Paraná, a população rural sofreu uma redução de 63,9\%. Dessa forma, a população urbana ultrapassou a população rural no Paraná na década de 1970, quando o percentual passou a ser representado por $41,07 \%$ da população ainda estabelecidos no campo e 58,93\% residindo nas cidades (MELO, 2011).

Assim, a modernização agrícola no Paraná alterou a estrutura fundiária do Estado principalmente em função da concentração de terras, êxodo rural, desemprego no campo com populações migrando para cidades polo regionais, outros Estados e regiões de fronteira e até mesmo para outros países, como o Paraguai, constituindo-se nos 'brasiguaios' (KLAUCK, 2012).

Como consequência desse processo excludente, proporcionado pela modernização agrícola no Paraná, principalmente a partir dos anos de 1970, ainda convivemos com conflitos sociais no cotidiano do campo paranaense, envolvendo atualmente boias-frias, trabalhadores semterra nos assentamentos em áreas rurais, principalmente em relação a reivindicações de auxílio governamental, desemprego no campo, direitos trabalhistas e disputas por terras.

Mesmo com a implantação do Programa Vilas Rurais em 1995, pelo governo paranaense ${ }^{14}$, no interior do Estado, a fim de amenizar os conflitos no campo, evitar o agravamento do êxodo para as cidades e buscar uma nova alternativa para o desemprego rural, não foi possível eliminar os problemas que envolviam a questão de disputa por terras e crescimento desordenado das grandes cidades paranaenses (MELO, 2011).

As propriedades distribuídas pelo governo por meio do Programa Vilas Rurais contam com aproximadamente $5.000 \mathrm{~m}^{2}$ e, em sua maioria,

14 Esse programa foi implantado no primeiro mandato do Governador Jaime Lerner (1995-1999) e executado pela Companhia de Habitação do Paraná (Cohapar). 
são caracterizadas pela diversificação da produção, com a predominância do cultivo do café e da associação com as agroindústrias de corte de frango, com o trabalhador assumindo todos os riscos da produção, além de obedecer às regras de manutenção, higienização, constituição da granja, qualidade do produto e entrega em período pré-determinado (MELO, 2011). Todo esse processo, além de conflituoso, se torna muito oneroso para os trabalhadores, a ponto de esses ou seus familiares terem que se deslocar até os centros urbanos para se empregarem em outra função a fim de complementar a renda.

Nesse sentido, podemos afirmar que o processo de modernização agrícola no Paraná ainda tem consequências nos dias atuais. A mudança na base técnica e produtiva da agricultura paranaense acompanhou um fenômeno nacional, representado na exclusão de um número considerável de trabalhadores do campo, fosse por meio do desemprego, êxodo rural ou pelo surgimento de novas modalidades de empregos formais ou informais, como os boias-frias, trabalhadores volantes ou temporários e até mesmo de novas formas de representações sociais, como no Movimento dos Trabalhadores Rurais Sem-Terra, nos assentamentos rurais, nas ocupações de terra e nas intensificações de conflitos sociais provenientes dessas disputas.

Algumas medidas emergenciais, como a implantação do Programa de Vilas Rurais, pelo Governo do Estado, ou de Assentamentos Rurais pelo Governo Federal, não eliminaram todos os problemas advindos da expulsão desses trabalhadores do campo com o processo de modernização. No caso das Vilas Rurais, o trabalho árduo e da baixa renda financeira força o trabalhador ou seus familiares a complementar sua renda em empregos na área urbana. Dessa forma, os beneficiados por esse programa acabam se constituindo em uma massa de trabalhadores volantes, que se identificam, muitas vezes, mais com o modo de vida urbano do que rural.

Esses são apenas alguns dos efeitos que abalaram as estruturas do meio rural na década de 1970. As alterações não ocorreram apenas em relação à concentração de terras, mas principalmente nas relações sociais 
estabelecidas historicamente no campo e que mudariam para sempre os rumos da agricultura nacional.

Por outro lado, não se pode ignorar que a modernização trouxe vários benefícios, principalmente econômicos. O Paraná se industrializou pelas políticas de incentivo ao desenvolvimento no país com o governo militar. De início, sua modernização era rudimentar, mas, com o passar dos anos, esse processo passou a ser aprimorado com a utilização de implementos agrícolas de última geração e de insumos, dentre outros produtos, que fizeram com que a produção do Paraná aumentasse consideravelmente. Essa modernização só foi possível pela mudança de culturas que não eram fáceis de serem mecanizadas, para culturas em que a mecanização era viável. Atualmente, o Estado é um dos principais produtores de soja ${ }^{15}$ no Brasil, porém não podemos esquecer o fato de que a produção de cana-de-açúcar vem se intensificando cada vez mais, gerando, assim, mais uma fonte de renda de suma importância para os produtores e para a economia estadual.

Diante dessas mudanças, somos levados a pensar a mecanização em um espaço mais amplo, não apenas no aspecto rural. Nesse sentido, podemos afirmar que o processo industrial gerou a modernização e a produção de uma nova gama de produtos. A busca pelo lucro se tornou constante e as novas tecnologias passaram a surgir a cada dia. A modernização do campo que levou ao êxodo rural no Paraná nas últimas décadas foi um processo acompanhado de adequações, mudanças e também de permanências, pois se trata de um processo que ainda tem desdobramentos nos dias de hoje.

\section{Referências}

GAGGERO, H.; GARRO, A. F.; MANTIÑAN, S. C. Historia de la América en los siglos XIX e XX. Buenos Aires: Aique, 2001.

15 Em 2011, o Estado do Paraná respondeu por aproximadamente 20\% da produção nacional de grãos, sendo o segundo maior produtor de soja no país, superado apenas pelo Estado de Mato Grosso. 
GONÇALVES NETO, W. Estado e agricultura no Brasil: política agrícola e modernização econômica brasileira (1960-1980). São Paulo: Hucitec, 1997.

MELO, N. A. Do complexo rural à modernização agrícola brasileira: a modernização da agricultura paranaense e os impactos na Vila Rural: uma análise do Programa Vilas Rurais no norte do Paraná. Revista Geografia em Atos, Presidente Prudente, v. 1, n. 11, p. 58-76, 2011.

MORO, D. A. A modernização da agricultura paranaense. In: VILLALOBOS, J. U. G. (Org.). Geografia social e agricultura. Maringá: Programa de Pós-Graduação em Geografia, 2000. p. 27-60.

KLAUCK, R. C. A luta dos brasiguaios pelo acesso à terra (1971-2006). 2012. $142 \mathrm{f}$.

Dissertação (Mestrado em História) - Universidade Estadual de Maringá, Maringá, 2012.

OLIVEIRA, F. A metamorfose da arribação: fundo público e regulação autoritária na expansão econômica do Nordeste. Novos Estudos Cebrap, São Paulo, n. 27, p. 1-48, 1990.

SILVA, J. G. A nova dinâmica da agricultura brasileira. Campinas: UNICAMP/IE, 1996. 